\title{
MANAGEMENT OF SIDEWALK MAINTENANCE TO IMPROVE WALKING COMFORT FOR SENIOR CITIZENS
}

\author{
MARIA VITTORIA CORAZZA, PAOLA DI MASCIO \& LAURA MORETTI \\ Sapienza University of Rome, Department of Civil, Building and Environmental Engineering, Rome, Italy
}

\begin{abstract}
When planning pedestrian facilities, comfort is a major requirement. Pedestrians decide to walk where they feel comfortable, and when they do not, they just detour from their route towards more comfortable ones. Filthy, distressed or too narrow sidewalks induce pedestrians to walk on the carriageways and this becomes extremely unsafe on routes usually walked by senior pedestrians, due to their vulnerability. Unsuitable pavements are due to two kinds of problems: on the one hand, irregularity of maintenance operations to restore evenness conditions after damages from shocks, weather phenomena or due to the installation of equipment which limit the availability of walkable surface; on the other, substandard execution of the pavements, with patches evidencing emergency operations. These problems can be solved with an appropriate maintenance management system: the choice of the adequate type as well as the timeliness of maintenance works can optimize the always limited resources of the roads managers. The paper deals with a methodology, Sidewalks Management System, derived from the most-known Road Management System. The method relies on surveys, classification and analysis of sidewalk distresses, adapting an index already standardized by ASTM for Roads and Airports: the Pavement Condition Index (PCI). PCI is modified to consider the specific types of distresses surveyed on the sidewalks. To validate the procedure a case study was performed at a residential district in Rome, where the lack of regular maintenance resulted into a network of unsafe sidewalks. Usual detours were surveyed and related to the level of distresses linked to the assessment of safety for senior pedestrians.
\end{abstract}

Keywords: sidewalks, maintenance, condition index.

\section{INTRODUCTION}

Pedestrians of every age are erratic. They decide to walk where they feel comfortable or attracted, and when they do not feel at ease, they detour from their route towards more comfortable ones. A typical example is represented by filthy, distressed or too narrow sidewalks which induce pedestrians to jaywalk or simply walk directly on the carriageways. Although extremely unsafe, this kind of behavior is quite common even among older pedestrians. The scientific literature in this field highlights the need of high-quality walking surfaces for older pedestrians (among these: [1]-[3]), but the real environment is often far from meeting such requirements. The maintenance is often neglected in urban areas and the well-known criteria of Pavement Management System (PMS) are scarcely applied by the municipalities all over the world [4], [5]. Unsatisfactory sidewalks conditions can be aggravated by adverse weather conditions, shocks, poor maintenance or cleaning, installation of inappropriate urban furniture or equipment, substandard execution, low quality materials, etc. Emergency operations sometimes represent the promptest solution to restore evenness conditions, as evidenced by the large number of patches. As a result sidewalks are not safe, nor comfortable, least of all attractive. Rome is no exception to all this and serves as a case in point to stress the need to plan regular sidewalks maintenance operations.

The paper deals with a methodology of Sidewalks Management System (SMS) derived from the most-known Road Management System. The method foresees survey, classification and analysis of sidewalk distresses, adapting an index that is already standardized by ASTM for Roads and Airports: the Pavement Condition Index (PCI). A case study, a residential 
district in Rome where the lack of regular maintenance resulted into a network of unsafe sidewalks, was used to validate the procedure. The paper describes the main outcomes and provides some final recommendations to improve the quality of sidewalks for the elderly.

\section{THE TRIESTE AREA CASE STUDY IN ROME}

According to the United Nations [6], population aging is unprecedented, pervasive and enduring. Life expectancy improves and, needless to say, all of the above is going to affect more and more everyday life in urban areas. At the same time, the vulnerability of senior citizens is long-time acknowledged in many fields, and especially for what concerns road safety. Again Rome is no exception. In 2013, the 623,460 citizens aged 65 and over accounted for about $21 \%$ of the Roman population [7]. Around $30 \%$ of them are aged 80 and over (i.e. 185,097 inh.): they are called the "great elderly" and it is expected that by 2020 they will account for the $7 \%$ of the total population. The majority of the population aged 65 and over lives in the most central areas of the city as, for instance, the Second District where about $6 \%$ of them are located. This district (subdivided into several smaller sub-districts, as in the picture from Table 1) is a typical Roman medium-to-high income, medium density area, built from the 1920 s to the 1960 s, where residential and business activities prevail.

The quality of the built environment is also high, with low-rise buildings (seldom exceeding five stories), landscaped areas (planted strips and plenty of vegetation), full provision of sidewalks, which make them ideal for walking. According to a study from the Municipality [8], the walking share in the local modal split was in 2006 higher than the Rome average (respectively 6.9 vs 5.6). Although no more recent data on local modal split are available, it is safe to assume that not much seems to be changed since. However, although ideal for walking the area is far from being a pedestrian realm.

Table 1: The case study district.

\begin{tabular}{|c|c|c|c|c|}
\hline \multicolumn{2}{|c|}{\begin{tabular}{|l} 
Indicators \\
\end{tabular}} & District 2 & District 2 area & Rome \\
\hline \multicolumn{2}{|c|}{ Inhabitants (units) } & 123,000 & & $2,800,000$ \\
\hline \multicolumn{2}{|c|}{ District area (sqkm) } & 13.67 & & $1,284.8$ \\
\hline \multicolumn{2}{|c|}{$\begin{array}{l}\text { Population density } \\
\text { (inh/sqkm) }\end{array}$} & 8,996 & & 2,180 \\
\hline \multirow{4}{*}{$\begin{array}{l}\text { Local } \\
\text { Modal } \\
\text { Split } \\
(\%)\end{array}$} & pedestrians & 6.9 & & 5.6 \\
\hline & transit & 10.3 & & 27.0 \\
\hline & passenger cars & 51.7 & & 52.1 \\
\hline & $\begin{array}{l}\text { powered two- } \\
\text { wheelers }\end{array}$ & 31.0 & & 15.3 \\
\hline \multicolumn{2}{|c|}{$\begin{array}{l}\text { Green areas ( } \% \text { of the } \\
\text { whole district area) }\end{array}$} & 22.1 & & 4.15 \\
\hline \multicolumn{2}{|c|}{$\begin{array}{l}\text { Pedestrian areas }(\% \text { of the } \\
\text { whole district area) }\end{array}$} & 0.01 & & 0.12 \\
\hline \multicolumn{2}{|c|}{$\begin{array}{l}\text { On-street parking areas } \\
(\% \text { of the whole district } \\
\text { area) }\end{array}$} & 0.6 & & 0.29 \\
\hline \multicolumn{2}{|c|}{$\begin{array}{l}\text { ZTLs (\% of the whole } \\
\text { district area) }\end{array}$} & 6.0 & & 2.1 \\
\hline
\end{tabular}




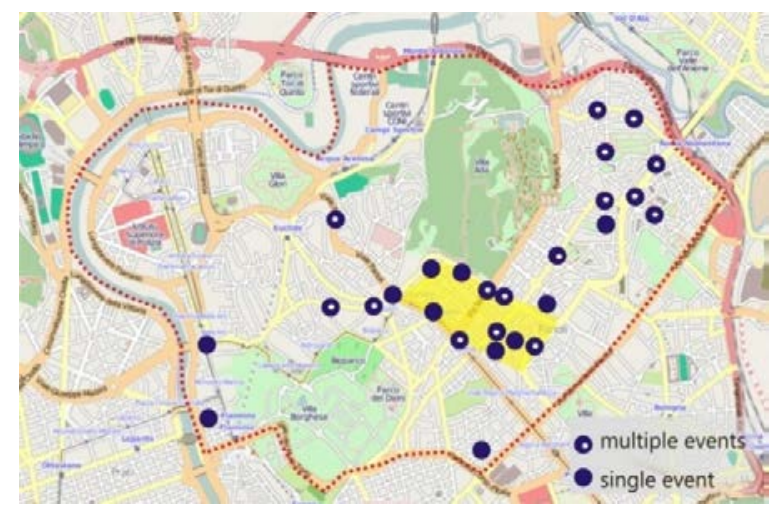

Figure 1: Black spots involving pedestrians aged 65 and over at the case study district, years 2010-2012.

If road safety data are considered, and especially those involving hit pedestrians aged 65 and over, black spots are concentrated in specific some areas and the larger, central cluster (yellow area in Fig. 1) is located in a residential zone, the so-called Trieste area.

It is largely acknowledged that more factors contribute to the occurrence of an accident, but in this case some recurring features of the built environment seem to have a major role in the events of the Trieste area. A survey from a previous study focused on two main squares of the Trieste area (Piazza Mincio and Piazza Caprera) and their surroundings highlighted that modest motorized traffic ( $<5000$ passenger cars/day estimated) and not negligible pedestrian flows ( $<4000$ pedestrians/day estimated) resulted into a walking occupancy of the carriageways (Fig. 2), with drivers below the speed limits and yielding priority to pedestrians [9]. A contributing factor was the sidewalks unsuitability, too narrow and uneven (mainly due to potholes, chinks and exposed tree roots) [10].

Although some functions and businesses changed in the surveyed areas in the last decade (a high school closed permanently in one square, a redesign program was carried out in the other, with sidewalks slightly broadened, and a number of new supermarkets opened nearby both), a recent survey confirmed the habits and the features already observed. Sidewalks maintenance was still poor and due to the same problems, pedestrians still favoured carriageways instead of sidewalks, traffic and pedestrian flows did not markedly change, drivers were still compliant with the speed limits. An element of variation was the increased amount of elderly pedestrians, especially in the morning hours. For this specific category, recurring activities observed were walking with shopping trolleys $35 \%$ of the surveyed flows) and pets $(25 \%)$ and strolling (30\%). Needless to say, the majority of them (around $65 \%$ ) performed such duties jaywalking, detouring from sidewalks or walking directly on the carriageways. Some recurring habits were also observed among the "great elderly" pedestrians: they walk preferably on the sunny side of the streets (the survey took place on average working days in wintertime, and probably the shadowed side would be favored in summertime); when carrying shopping bags or walking pets, they tend to avoid areas perceived as too narrow or crowded (due to furniture, trees, etc.), even when actually there is plenty of room; once left the sidewalk for any of the reason above mentioned, they continue to walk on the carriageways until they have to cross again the street. Often, they stop on the carriageway to talk or rest and then resume walking. 

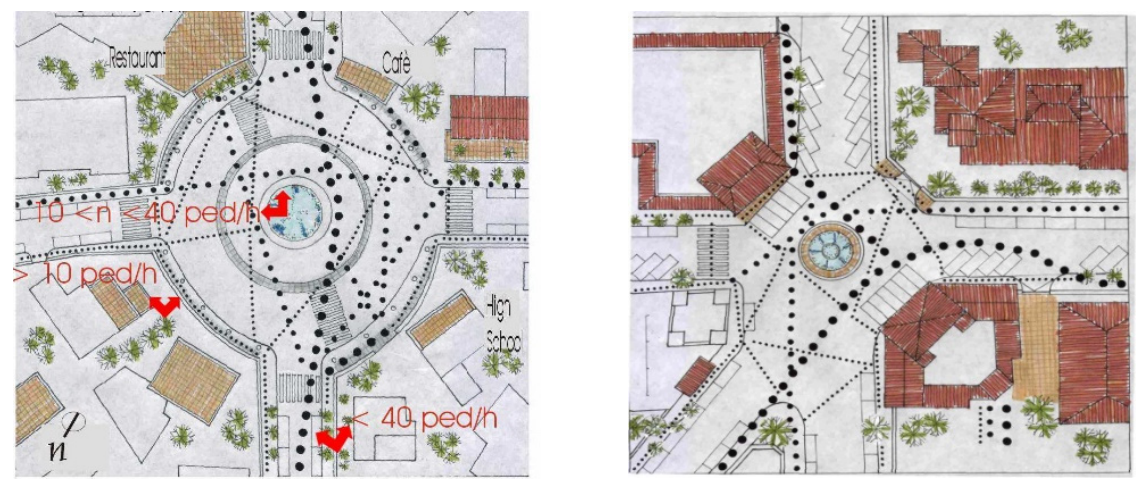

Figure 2: Pedestrians routes at two squares in the study area [9].

\section{THE METHODOLOGICAL APPROACH TO IMPROVE SAFETY FOR SENIOR PEDESTRIANS}

The observation of recurring behaviors and black spots in the surveyed areas evidenced the unsuitability and poor safety of the sidewalk network in the case study though the years. The research question was then to assess the feasibility of a dedicated maintenance management system, to improve the quality of pavements and have them more attractive and safer for elderly pedestrians, according to a three-step procedure:

- Set up of tools to identify the test field in the study area;

- Definition of a sidewalk condition index and its application to the test field, in light of prospective maintenance management plans;

- Analysis of results.

\subsection{The test field}

As said, pedestrians walk everywhere and the built environments of two surveyed areas are alike. The identification of a restricted area or test field for the assessment of dedicated maintenance management system was then based on the results of several check lists aimed at assessing the "walkability" of the environment around the two squares, connected with the location of black spots. Although walkability lists abound in grey and scientific literature, in this case a set of dedicated lists was used, each addressing a specific issue: comfort, safety, accessibility, attractiveness, and associated to each street connecting each square.

Each list included more requirements to be scored, according to the following criteria:

- "adequate" if the requirement was met for more than $75 \%$ of the street (corresponding to score: 2);

- "to be improved" if the requirement was met between 50 and $75 \%$ of the street (corresponding to score: 1);

- "poor" if the requirement was met for less than 50 of the street (corresponding to score: 0).

Scores were provided qualitatively, according to a visual inspection of each street and those with the lowest scores, i.e. "poor" streets, became eligible for the selection. The 
criterion of continuity was then introduced: "poor" streets connecting each other were clustered so to have "poor" routes. These routes associated with black spots could be eventually selected as candidate test fields.

At the end of this process one area resulted more appropriate than the others due to the additional higher recurrence of accidents involving elderly pedestrians (Fig. 3). In this 5500 $\mathrm{m}^{2}$ area, called the Trieste Test Field (TTF), the whole pedestrian pavements network was analysed, with exclusion of the private access areas, where sidewalks are interrupted (for example by driveways), as further described.

Pedestrian flows in the TTF were slightly higher (about $>50$ pedestrians/h along the "poor" route) than the average surveyed in the whole area; again, in the morning hours the amount of elderly pedestrians walking alone was around 35\%, a not negligible group if compared to the other ones observed, i.e. $25 \%$ youngsters (two high schools are nearby) and $40 \%$ aged in-between. For what concerns pedestrians walking in groups (two to four people), percentages slightly change: $38 \%$ youngsters, $39 \%$ elderly (the majority of groups formed by one elderly and one younger person, usually a caregiver) and $23 \%$ people aged in-between. To be noted that, according to observations, the presence of an accompanying person does not lead to safer behaviours: jaywalking or walking on the carriageway until crossing were both solo and in group; group walking may seem therefore to foster the feeling of safety also when walking behaviours might be risky.

\section{STUDY OF THE SIDEWALK CONDITION INDEX IN THE TEST FIELD}

Once the TTF was identified, the study progressed with the analysis of sidewalks and the assessment of the applicability of the Sidewalks Management System (SMS) derived from the most-known Road Management System. The method relies on more surveys, classifications and analyses of sidewalk distresses, adapting an index already standardized by the American Society for Testing and Materials (ASTM) for Roads and Airports: the Pavement Condition Index (PCI), as further described.

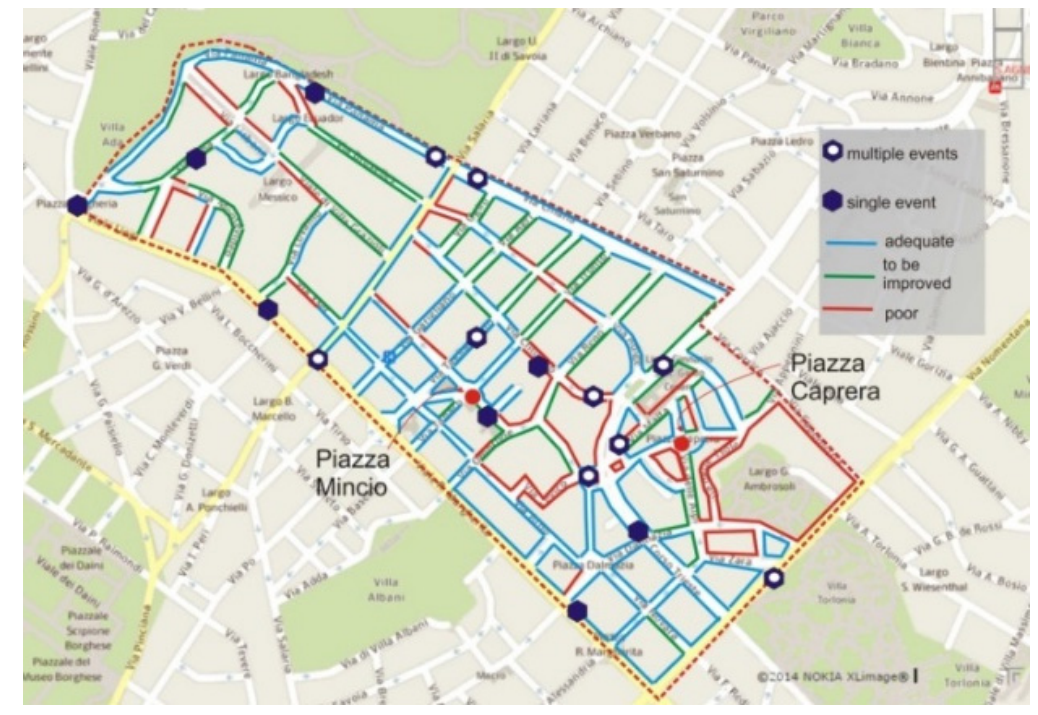

Figure 3: The TTF. 


\subsection{Defining the Sidewalk Condition Index (SCI)}

Since the 1970s, when the concepts of maintenance management system started to be applied to roads, the attention of the experts focused mostly on the Pavement Management System (PMS). During the 1980s, and particularly after the first North American Pavement Management Conference held in Toronto, Canada, in 1985, PMS were recognized to be a major tool to aid the road engineers. Since then, PMS has been extensively used by road administrations worldwide to define maintenance and rehabilitation strategies for the pavements of the road networks under their jurisdiction [11]. A PMS includes several steps: pavement distresses survey, pavement evaluation, life cycle cost analysis and, finally, definition of maintenance strategies. A proper definition of PMS allows to reduce the road overall costs (construction and maintenance) as well as the disruption to traffic.

Although mobility has always dealt with the vehicular traffic, as a consequence of cultural and economic reason, recently, the increasing attention to environmental impacts and road safety has steered the research towards sustainable mobility, and particularly pedestrian mobility. In line with such trend, the TTF application, a Sidewalks Condition Index (SCI) was studied to quantify the sidewalk conditions and the amount of the distresses that can be dangerous and uncomfortable for pedestrians, transferring a knowledge from the field of motorized traffic. Consequently, the SCI was derived from the Pavement Condition Index (PCI), largely acknowledged in the scientific literature and practice. The PCI is a numerical indicator that rates the surface condition of the pavement. It provides a measure of the current conditions of the pavement based on the distresses observed on the pavement surface that indicate both structural integrity and surface operational conditions (localized roughness and skid resistance). The PCI ranges from 0 to 100 , with 0 being the worst possible condition and 100 being the best possible one [12]. The PCI provides feedback on pavement performance for validation or improvement of current pavement design and maintenance procedures. The PCI was standardized both for airports (ASTM D 5340-11) and roads (ASTM D 6433-11), since 1998. With the aim to define the SCI, a catalogue of distresses on the pavements in the TTF was produced. The pavements were divided in branches and in sections. The first ones are identifiable parts of the network (for example a given link with its own street name, or more links under the same street name). Since branches are typically large units of the pavement network, they are divided into smaller components called "sections", for managerial purpose. A section is a contiguous pavement area having uniform features (construction, maintenance, usage history, and conditions). Each section is divided into sample units that are portions of a pavement section, only for the purpose of pavement inspection.

The PCI method states the reference dimension of the sample unit to have a statistical significance of the survey. The method also comprehends several kinds of pavements (asphalt, concrete, unpaved), but in this study only the asphalt ones were considered, being these not only the most recurring in Italy, but also the only ones available in the TTF. A sample unit is defined as an area $225 \pm 90 \mathrm{~m}^{2}$ for asphalt surfaced roads and $450 \pm 180 \mathrm{~m}^{2}$ for asphalt surfaced airfield. In the TTF case, the dimension of pedestrian sample unit was defined by extrapolating these measures as a function of the width of roads and airports. As shown in Table 2, the runway width can vary from 20 to $60 \mathrm{~m}$, while the road width is generally included between $10 \mathrm{~m}$ and $30 \mathrm{~m}$ and the sidewalk width between $1.5 \mathrm{~m}$ (minimum generally recommended worldwide to accommodate wheelchair users) and $10 \mathrm{~m}$. These are also coherent with the Italian enforced standards. The minimum and maximum values of the areas set in the PCI method was correlated with the minimum and maximum width of roads 
and airport and the width of the sidewalk sample unit was then derived proportionally, as in Table 2, thus resulting into a reference value of $100 \pm 50 \mathrm{~m}^{2}$.

\subsection{The distress survey on the asphalt pedestrian pavements}

According to the PCI method, distresses on the asphalt pedestrian pavement can be classified as follows: 1. Block cracking; 2. Diffused cracking; 3. Linear cracking; 4. Patching and Utility Cut Patching; 5. Potholes; 6. Corrugation; 7. Bleeding; 8. Ravelling; 9. Weathering; 10. Deformation due to roots; 11. Deformation due to run-off water; 12. Differential settlement of the pavement sub-base layers compared to the interspace of buildings; 13 . Depressions and 14. Edge disruption. A specific distresses registry was designed for the TTF. This was composed of multiple sheets, each for any distress to measure in terms of size and severity. Fig. 4 shows two typical distresses of pedestrian pavements as an example: potholes and deformation due to roots, along a street at the TTF.

Table 2: Definition of sample unit area for asphalt surfaced sidewalk.

\begin{tabular}{|l|c|c|c|}
\hline Infrastructure & Runway & Road & Sidewalk \\
\hline Minimum width $(\mathrm{m})$ & & & 10 \\
\hline Minimum area $\left(\mathrm{m}^{2}\right)$ & 20 & 135 & 1,5 \\
\hline Maximum width $\left(\mathrm{m}^{2}\right)$ & 60 & 30 & 10 \\
\hline Maximum area $\left(\mathrm{m}^{2}\right)$ & 630 & 315 & 150 \\
\hline
\end{tabular}

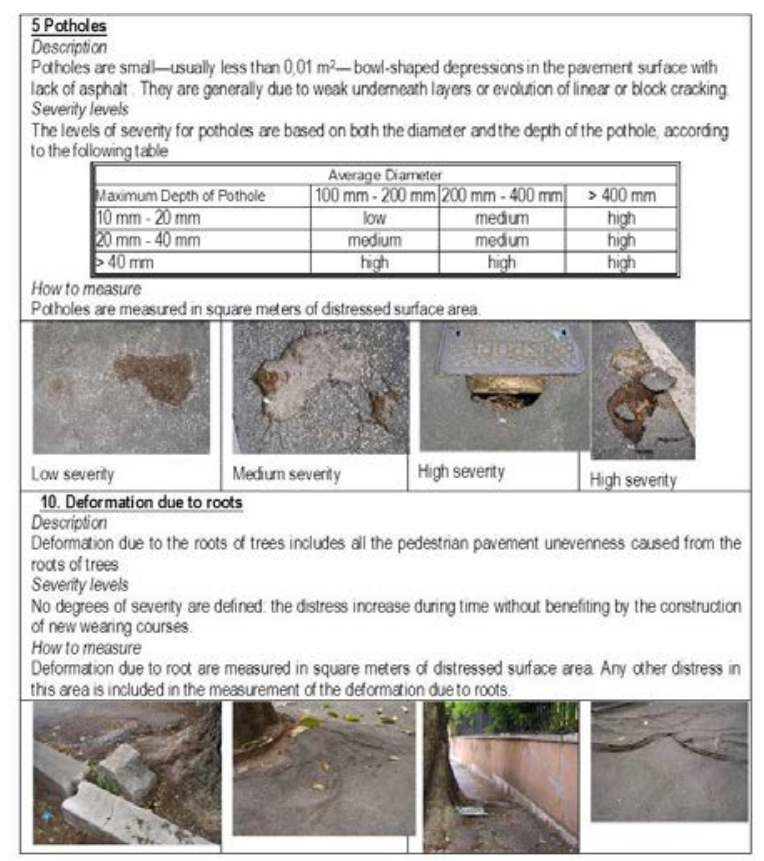

Figure 4: Catalogue of distresses of pedestrian asphalt pavements: examples of two sheets. 
The survey is just visual and data can be recorded in a data sheet similar to that one shown in section 4.3 in Fig. 8. For each sample unit, geometrical features (area, section, branch, code), survey date, amount and severity level of the distresses were recorded. The name, the code and the area of the 23 surveyed branches $\left(\mathrm{R}_{\mathrm{i}}\right.$, subdivided into "even" and "odd" sides corresponding to the local street numbering), sections $\left(\mathrm{S}_{\mathrm{i}}\right)$ and sample units $\left(\mathrm{U}_{\mathrm{i}}\right)$ are listed and Table 3 provides an example where branches corresponding to the odd sides are reported.

Fig. 5 shows the density of the recorded distresses in the TTF. Highest density (more than $50 \%$ ) is associated to: patching (4), potholes (5), corrugations (6) and depressions (13).

Table 3: Division in branches (Ri), sections ( $\mathrm{Si}$ ) and sample units (Ui) for the distress survey activity on the pavements at the TTF.

\begin{tabular}{|l|c|c|c|c|c|c|}
\hline \multicolumn{2}{|c|}{$\begin{array}{c}\text { Branch } \\
\text { odd) }\end{array}$} & $\begin{array}{c}\text { Branch } \\
\text { area } \\
\left(\mathrm{m}^{2}\right)\end{array}$ & Section & $\begin{array}{c}\text { Section } \\
\text { area }\left(\mathrm{m}^{2}\right)\end{array}$ & $\begin{array}{c}\text { Number } \\
\text { of sample } \\
\text { unit }\end{array}$ & $\begin{array}{c}\text { Sample } \\
\text { unit code }\end{array}$ \\
\hline Via Brenta & $\mathrm{R}_{2}$ & 222,32 & $\mathrm{~S}_{2}$ & 222,32 & 2 & $\mathrm{U}_{3} ; \mathrm{U}_{4}$ \\
\hline Via Serchio & $\mathrm{R}_{4}$ & 426,61 & $\mathrm{~S}_{4}$ & 426,61 & 4 & $\begin{array}{c}\mathrm{U}_{6} ; \mathrm{U}_{7} ; \mathrm{U}_{8} ; \\
\mathrm{U}_{9}\end{array}$ \\
\hline Via Ticino & $\mathrm{R}_{6}$ & 204,36 & $\mathrm{~S}_{6}$ & 204,36 & 2 & $\mathrm{U}_{12} ; \mathrm{U}_{13}$ \\
\hline Via Alpi & $\mathrm{R}_{13}$ & 103,58 & $\mathrm{~S}_{16}$ & 103,58 & 1 & $\mathrm{U}_{37}$ \\
\hline Via Malta & $\mathrm{R}_{15}$ & 412,66 & $\mathrm{~S}_{18}$ & 412,66 & 4 & $\begin{array}{c}\mathrm{U}_{42} ; \mathrm{U}_{43} ; \\
\mathrm{U}_{44} ; \mathrm{U}_{45}\end{array}$ \\
\hline Via Sebenico & $\mathrm{R}_{17}$ & 100,81 & $\mathrm{~S}_{20}$ & 100,81 & 1 & $\mathrm{U}_{47}$ \\
\hline Corso Trieste & $\mathrm{R}_{19}$ & 382,01 & $\mathrm{~S}_{22}$ & 382,01 & 3 & $\begin{array}{c}\mathrm{U}_{55} ; \\
\mathrm{U}_{56} \mathrm{U}_{57}\end{array}$ \\
\hline Via Clitunno & $\mathrm{R}_{23}$ & 149,19 & $\mathrm{~S}_{26}$ & 149,19 & 1 & $\mathrm{U}_{65}$ \\
\hline
\end{tabular}

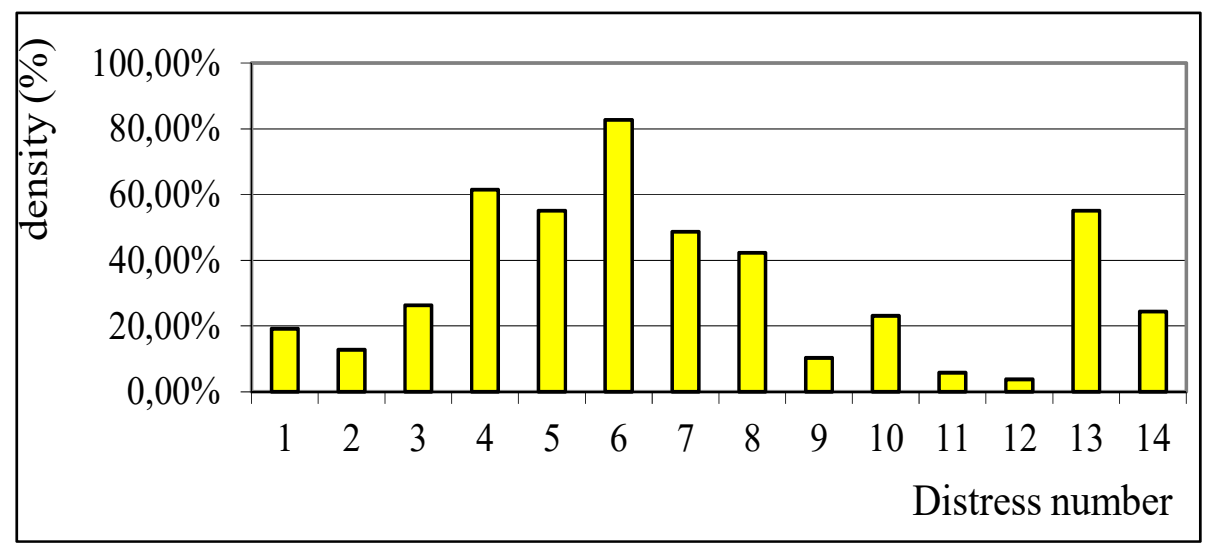

Figure 5: Distress density on the TTF sidewalks. 


\subsection{The calculation of the Sidewalk Condition Index (SCI)}

As the PCI, the SCI ranges between 0 and 100, with 0 being the worst possible condition and 100 being the best possible one and it can be calculated as

$$
S C I=100-C D V,
$$

where $\mathrm{CDV}$ is the correct deduct value that considers the relation among the several distresses.

CDV can be calculated according to a four-step procedure:

1. Definition of distress per cent density of each type of distress $i$ at each severity level;

2. Calculation of the deduct value (DV) for each distress;

3. Calculation of the total deduct value (TDV) adding all the partial deduct values;

4. Definition of the correct deduct value (CDV).

The four steps are described as follows:

1) Definition of distress per cent density of each type of distress $i$ at each severity level $\mathrm{j}$ as:

$$
d \%=\frac{A_{\text {distress }}}{A_{u}} \times 100,
$$

where $\mathrm{A}_{\mathrm{u}}$ is the sample unit area and $\left(\mathrm{A}_{\text {distress }}\right)$ is the total area for each type of distress $i$ at each severity level $j$.

2) Calculation of the deduct value (DV) for each distress as:

$$
D V_{i j}=p_{i j} * F_{i}(d \%) \text {, }
$$

where $\mathrm{DV}_{\mathrm{ij}}$ is the deduct value and $F_{i}$ is the value resulting from the per cent density $d \%$, for the distress $i$, by curves like those in Fig. 6 . These curves were calculated by a proportion assigning the maximum value, equal to 100 , to the maximum density. The deduction curves derive by interpolating these values and the recorded density, and restraining the curve to pass in the points $(0,0)$ and $(100,100)$. The curves are one for each distress and they are exponential. Fig. 6 shows those related to the distresses in Fig. 4. Interviews to pedestrians who walked the TTF allowed defining a weight, $p_{\mathrm{ij}}$. The panel of interviewees was representative of the average pedestrian population of the TTF, thus included also elderly and physically challenged pedestrians.
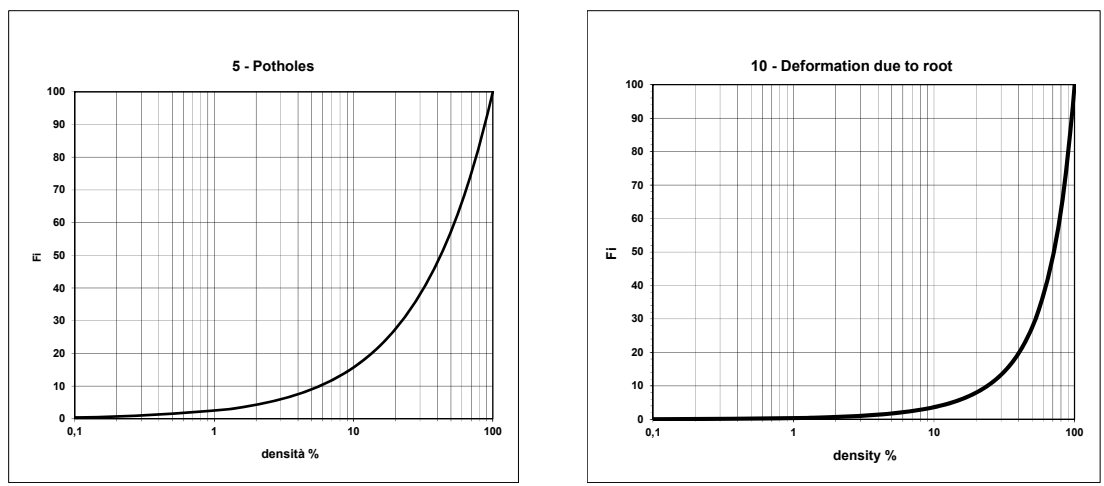

Figure 6: Distress density on sidewalks in the TTF. 
Table 4: Distress weights.

\begin{tabular}{|c|c|c|c|c|c|c|c|c|c|c|c|c|}
\hline distress & $1 \mathrm{~L}$ & $1 \mathrm{M}$ & $1 \mathrm{H}$ & $2 \mathrm{~L}$ & $2 \mathrm{M}$ & $2 \mathrm{H}$ & $3 \mathrm{~L}$ & $3 \mathrm{M}$ & $3 \mathrm{H}$ & $4 \mathrm{~L}$ & $4 \mathrm{M}$ & $4 \mathrm{H}$ \\
\hline weight & 0,2 & 0,4 & 0,8 & 0,3 & 0,5 & 0,7 & 0,2 & 0,4 & 0,6 & 0,2 & 0,4 & 0,8 \\
\hline distress & $5 \mathrm{~L}$ & $5 \mathrm{M}$ & $5 \mathrm{H}$ & 6 & $4 \mathrm{H}$ & $7 \mathrm{~L}$ & $7 \mathrm{M}$ & $7 \mathrm{H}$ & 8 & $9 \mathrm{~L}$ & $9 \mathrm{M}$ & $9 \mathrm{H}$ \\
\hline weight & 0,2 & 0,8 & 1,2 & 0,5 & 0,8 & 0,3 & 0,5 & 1,2 & 0,1 & 0,1 & 0,4 & 1,2 \\
\hline distress & 10 & 11 & 12 & $13 \mathrm{~L}$ & $13 \mathrm{M}$ & $13 \mathrm{H}$ & $14 \mathrm{~L}$ & $14 \mathrm{M}$ & $14 \mathrm{H}$ & & & \\
\hline weight & 0,8 & 0,2 & 0,2 & 0,1 & 0,5 & 1 & 0,1 & 0,3 & 0,5 & & & \\
\hline
\end{tabular}

All the interviewees provided homogeneous assessments, often consistent with level of service evaluated with the proposed SCI. Among them, the most vulnerable ones (those with walking aids), those who had some kind of walking impairment (persons in wheelchairs) and the elderly pedestrians expressed more severe evaluations: these groups of people should be considered for calibrating model. In general, the interviewees indicated the heavier distresses as high severity block cracking, high severity patching, high severity potholes and deformation due to roots. On the contrary, those assessed as less heavy were: linear cracking, bleeding, weathering and edge disruption, all with low severity levels. The resulted weights are listed in Table 4.

3) Calculation of the total deduct value (TDV) adding all the partial deduct values as:

$$
T D V=\sum_{i=1}^{14} \sum_{j=1}^{3} D V_{i j},
$$

where $i$ is the number of distress type (from 1 to 14$) ; j$ is the severity level $(1=$ low, $2=$ medium, 3 = high).

4) Definition of the correct deduct value (CDV) as the TDV must be corrected to consider the mutual dependency of some distresses. Neglecting to consider this, TDV can then result too high $(>100)$ and it cannot reflect the actual condition of the pavement. The correction curves were drawn by fitting the TDV of all the surveyed sample units with the score given from the sample of pedestrians walking on the same units under different conditions (carrying bags, trolleys, prams...). The score ranges from 0 (worse assessment) to 10 (best assessment). For each sample unit, the average score, its difference to 10 and the correspondent value expressed in hundredths were calculated. When TDV is $<30$, no correction is needed; on the contrary, when TDV is $>30$ and there is more than one distress with a density $>$ than $2 \%$, TDV has to be corrected. In Fig. 7, five curves were drawn related to a number of distresses $\mathrm{c}_{\mathrm{r}}$ variable from 1 to 5 . When $\mathrm{c}_{\mathrm{r}}=1$ no correction is needed.

Fig. 9 shows the SCI results, as graphically reported. The red line indicates SCI values $<50$, while the green line those $>50$. Fig. 10 also serves to address two more issues, the first of which is the need to plan regular maintenance operations not only according to the distress severity, but also considering continuity of paths and quality and quantity of pedestrian flows. This is particularly true in areas, such as the TTF, where elderly pedestrians walking behaviors tend to concentrate on some legs or features of their routes (the above mentioned "sunny side" of the street, "empty" sidewalks vs. crowded, etc.).

The second issue is related to planted strips, where deformations due to exposed roots cannot be solved only by interventions to repair sidewalks per se. Experts of local botany and gardening, and landscapers should be involved in the maintenance plans, as well.

In Fig. 8 an example of SCI calculation is reported. 


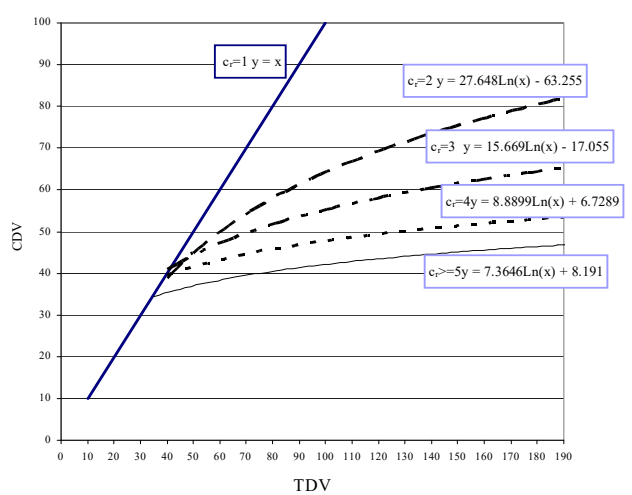

Figure 7: Distress density on sidewalks in the TTF.

\begin{tabular}{|c|c|c|c|c|c|c|c|c|c|c|}
\hline \multicolumn{10}{|c|}{ PEDESTRIAN ASPHALT PAVEMENT - CONDITION SURVEY DATA SHEET FOR SAMPLE UNIT } & \\
\hline Branch & R1 & \multicolumn{3}{|c|}{ Section } & s1 & \multicolumn{2}{|c|}{ Sample unit } & U2 & & \\
\hline Branch Area $\mathrm{m}^{2}$ & 213,11 & & Date & & $07 / 12 / 201$ & Sample & trea $\mathrm{m}^{2}$ & 132,58 & & \\
\hline \multirow{2}{*}{\multicolumn{7}{|c|}{\begin{tabular}{|l|l|} 
1. Block Cracking & 6. Corrugation \\
2. Diffused cracking & 7. Bleeding \\
\end{tabular}}} & \\
\hline & & & & & & & \multirow{2}{*}{\multicolumn{4}{|c|}{ 12. Differential settlement of the pavement sub-base }} \\
\hline \multicolumn{3}{|c|}{$\begin{array}{l}\text { 2. Diffused cracking } \\
\text { 3. Linear cracking }\end{array}$} & \multicolumn{4}{|c|}{$\begin{array}{l}\text { 7. Bleeding } \\
\text { 8. Ravelling }\end{array}$} & & & & \\
\hline \multicolumn{3}{|c|}{ 4. Patching and Utility Cut Patching } & \multirow{2}{*}{\multicolumn{4}{|c|}{$\begin{array}{l}\text { 9. Weathering } \\
\text { 10. Deformation due to roots }\end{array}$}} & \multicolumn{4}{|c|}{ 13. Depressions } \\
\hline \multicolumn{3}{|c|}{ 5. Potholes } & & & & & 14. Edge & disruption & & \\
\hline Distress Type & \multicolumn{7}{|c|}{ Quantity } & Total & $\begin{array}{c}\text { Density } \\
\%\end{array}$ & $\mathrm{DV}_{\mathrm{i}}$ \\
\hline $4 \mathrm{M}$ & 1,19 & 0,03 & & & & & & 1.22 & 0.92 & 0,65 \\
\hline $5 \mathrm{~A}$ & 0.7 & 0.49 & 0,56 & 0,56 & 0,74 & 0,64 & 1.84 & 5.53 & 4.17 & 10,54 \\
\hline $5 \mathrm{~A}$ & 0,74 & 0,49 & & & & & & 1,23 & 0,93 & 3,15 \\
\hline 6 & 0,18 & 0,18 & 1,25 & 0,18 & 0,2 & 0,16 & 1.02 & 3,17 & 2,39 & 3,37 \\
\hline 6 & 0,25 & 0,2 & 0,15 & & & & & 0,6 & 0,45 & 1,28 \\
\hline $7 \mathrm{~B}$ & 0,06 & & & & & & & 0,06 & 0,05 & 2,01 \\
\hline $7 \mathrm{~A}$ & 0,16 & 1,52 & 4 & 1,44 & 0,6 & 4,48 & 8.24 & 20,44 & 15,42 & 12,15 \\
\hline $7 \mathrm{~A}$ & 0,32 & & & & & & & 0,32 & 0,24 & 8,08 \\
\hline $13 \mathrm{~B}$ & 0,14 & 0,14 & 0,15 & & & & & 0,43 & 0,32 & 0,38 \\
\hline & 0,12 & & & & & & & 0,12 & 0,09 & 1,84 \\
\hline \multirow[t]{5}{*}{$14 \mathrm{~A}$} & 0,4 & & & & & & & 0,4 & 0,30 & 7,50 \\
\hline & & & & & & & & & & \\
\hline & & & & & & & & & $\mathrm{TDV}=$ & 50,94 \\
\hline & & & & & & & & & CDV $=$ & 28 \\
\hline & & & & & & & & & $\mathrm{SCl}=$ & 72 \\
\hline
\end{tabular}

Figure 8: Example of SCI calculation in TTF.

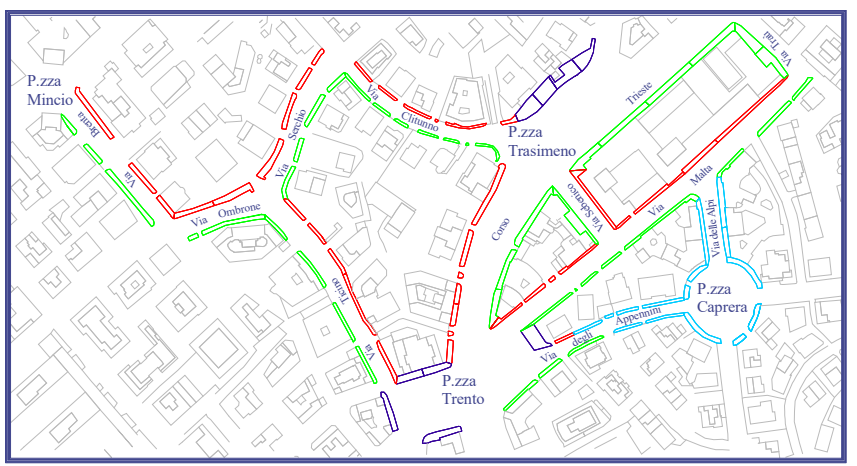

Figure 9: Result of SCI calculation in the TTF.

\section{CONCLUSIONS}

The study so far described is a first attempt to transfer assessment methodologies usually applied within maintenance programs for motorized modes infrastructures to sidewalks. 
The study still requires more validation analyses on more test sites and groups of users different from those involved in the TTF (for example, younger). Therefore, the curves and the correct deducted values are not definitive and amendments are expected to occur, as long as more different users groups will be included. However, interviewed elderly pedestrians reported a very accurate perception of risks related to sidewalks unsuitability (high severity block cracking, patching, potholes and roots deformations), but they seem to be not fully aware of the risks due to their behavior. Recurrently observed jaywalking or walking on the carriageways convert, de facto, the street into a naturally-shared space between motorized users and elderly pedestrians (also helped by the low speed driving of the former), but in somehow this experienced mix of walking both on the carriageways and sidewalks, seems to be not perceived as an additional element of risk by the latter.

The TTF experience and the applied method can help road managers define priorities in the maintenance works just according to the SCI values derived from the visual surveys, which stresses the importance of having pedestrians actively involved the risk assessment.

\section{REFERENCES}

[1] Dunbar, G. et al., Older pedestrians: A critical review of the literature. Road Safety Research Report, 37, Department for London: London, 2004.

[2] Heinonen, J.A. \& Eck, J.E., Pedestrian Injuries and Fatalities, Guide 51, U.S. Department of Justice, Office of Community Oriented Policing Services, Online. http://www.popcenter.org/problems/pdfs/PedestrianInjuries.pdf. Accessed on: 2 May 2015, 2007.

[3] Zegeer, C.V. et al., PEDSAFE 2013: Pedestrian safety guide and countermeasure selection system. U.S. Department of Transportation, Federal Highway Administration, Online. http://www.pedbikesafe.org/PEDSAFE/index.cfm. Accessed on: 2 May 2015.

[4] Loprencipe, G., Pantuso, A. \& Di Mascio, P., Sustainable pavement management system in urban areas considering the vehicle operating costs. Sustainability, 9(3), pp. 453-468, 2017.

[5] Loprencipe, G. \& Pantuso, A., A specified procedure for distress identification and assessment for urban road surfaces based on PCI. Coatings, 2017.

[6] United Nations. World Population Aging 1950-2050, Online. http:// www.un.org/esa/population/publications/worldageing19502050/. Accessed on: 2 May 2015, New York, 2002.

[7] Rome Municipality. Open data, Popolazione e Società, Online, http:// dati.comune.roma.it/download/popolazione-e-societa. Accessed on: 2 May 2015.

[8] Cecconi, N., Vivere a Roma, Rome Municipality, Rome, 2007.

[9] Corazza, M.V. \& Di Mascio, P., How to make traffic calming more walking friendly: Directions to increase intersections performances for pedestrians, Proceedings of the Extra Workshop ICTCT Safe non-motorised traffic. Planning, evaluation, behavioural, legal and institutional issues, pp. 1-16, 2003.

[10] Corazza, M.V., Di Mascio, P. \& Moretti, L., Managing sidewalk pavement maintenance: A case study to increase pedestrian safety. Journal of Traffic and Transportation Engineering, 3(3), pp. 203-214, 2016.

[11] Ferreira, A., Picado-Santos, L. \& Antunes, A.A., Segment-linked optimization model for deterministic pavement management systems. The International Journal of Pavement Engineering, 3(2), pp. 95-105, 2002.

[12] Shahin, M.Y., Pavement Management for Airports, Roads, and Parking Lots. Kluwer Academic Publishers: Dordrecht, 2005. 